\title{
DeVEloping An InTElligent SySTEM For Prediction OF OPTIMAL DoSE OF WARFARIN in Iranian Adult Patients With Artificial Heart Valve
}

\author{
Maryam Aghazadeh ${ }^{1}$, Azam Orooji ${ }^{2 *(D)}$, Mehran Kamkar Haghighi $^{3}$
}

${ }^{1} \mathrm{MSc}$ in Medical Informatics, Department of Health Information Management, Tehran University of Medical Sciences, Tehran Iran. ${ }^{2}$ Assistant Professor, Bojnord University of Medical Sciences, Bojnord, Iran.

${ }^{3}$ Department of Computer Engineering, Institute of Technology, University of Ontario, Ontario, Canada.

\begin{tabular}{ll}
\hline Article Info & A B S T R A C T \\
\hline $\begin{array}{l}\text { Article type: } \\
\text { Innovation in Health Informatics }\end{array}$ & Introduction: \\
\hline Article History: & Artificial intelligence (AI) research within medicine is growing rapidly. AI is \\
Received: $2019-11-04$ & poised to transform medical practice. AI has been studied in several areas \\
Revised: - & of healthcare and medical practice, including diagnosing, treating and \\
Accepted: 2019-12-23 & caring of patients. Warfarin is one of the most commonly prescribed oral \\
& anticoagulant. Among all anticoagulants, warfarin has long been listed \\
& among the top ten drugs causing adverse drug events. Due to narrow \\
* Corresponding author: & therapeutic range and significant side effects, warfarin dosage \\
Azam Orooji & determination becomes a challenging task in clinical practice. The purpose \\
Assistant Professor, Bojnord & of this study was to determine exact dose of warfarin needed for patients \\
University of Medical Sciences, & with artificial heart valve using artificial neural networks (ANN). \\
Bojnord, Irand
\end{tabular}

Bojnord, Iran.

Email: orooji_9898@yahoo.com

\begin{abstract}
Development:
To achieve the best model, some multi-layer perceptron ANNs were constructed with different structures. The dataset used included 846 patients who had been referred to the PT clinic in Tehran heart center in the second six months of the year 2013. Finally, the best structure of ANN for warfarin dose was investigated and used for prediction system developments. In this paper the implementation of ANNs and proposed system in MatLab environment are described.

\section{Application:}

The effectiveness of ANNs were evaluated in terms of classification performance using 10 fold cross-validation procedure and the results showed that the best model is a network that has 7 neurons in its hidden layer with an average absolute error of 0.1 , disturbance rate of 0.33 and regression of 0.87 .
\end{abstract}

\section{Conclusion:}

The achieved results reveal that ANN-based system is a suitable tool for warfarin dose prediction in Iranian patients with an artificial heart valve. However, no system can be guaranteed to achieve $100 \%$ accuracy, but using such methods can reduce medical errors and thereby improve health care and patient safety.

Keywords:

Neural Networks, Machine Learning, Warfarin Dosing

How to cite this paper

Aghazadeh M, Orooji A, Kamkar Haghighi M. Developing an Intelligent System for Prediction of Optimal Dose of Warfarin in Iranian Adult Patients with Artificial Heart Valve. 2019; 8(1): e25. DOI: 10.30699/fhi.v8i1.213

\section{INTRODUCTION}

Cardiovascular disease was recorded as the leading cause in $31 \%$ of all death, with more than 17.5 million deaths each year [1]. The number of cardiovascular disease including heart disease and stroke is expected to rise to more than 23.6 million by 2030 [2]. The percentage of premature deaths (under the age of 70) from CVDs ranges from $4 \%$ in high-income countries to $42 \%$ in low-income countries [3] . Warfarin is the most widely used anticoagulant in the prevention and treatment of CVD. Warfarin is often used to prevent thrombosis and occlusion of blood flow disorders at fibrillation, Deep Venus Thrombosis (DVT), heart attacks, 
pulmonary embolism and heart valve replacement [4-7]. Due to large inter-individual variability in dose requirements, the warfarin dosage in anticoagulation is usually complicated and unpredictable [요, $\underline{9}$ ]. Under- or over- dosing will result in INR values outside the target range (2-3 for most conditions) and put the patient at risk of severe adverse outcomes such as bleeding or thromboembolism and it can exacerbate disease, hospitalization, and even death $[\underline{4}, \underline{5}, \underline{10}]$.

Many clinical and genetic features affect the dosage of patients $[\underline{5}, \underline{9}, \underline{11}]$ therefore, machine learning techniques can be used for the diagnosis or prediction of warfarin's doses to help expert humans to make the best decisions $[\underline{12}, \underline{13}]$. Artificial Neural Networks (ANNs) are one of the most important ML algorithms [14] which are apt for such applications as: first, they can incorporate large number of inputs and large number of outputs; second, they are dynamic and can be upgraded with new data sets periodically; third, they can explore the nonlinear relationship; forth, they have high generalizability $[\underline{15}, \underline{16}]$ and hence, can be used to predict warfarin dosage requirements.

In this paper, the Multilayer Perceptron (MLP) as common type of ANNs was used. Aim of this study is to find the best MLP structure based on conjugate gradient training algorithm. Then, the next step is to develop an intelligent system for prediction of optimal dose of warfarin that is suitable for Iranian adult patients with artificial heart valves.

\section{DEVELOPMENT}

First, a list of essential factors for warfarin dose determination was made by search the electronic databases and consultation with cardiologists. Then these factors were organized in the form of a questionnaire "Determining the importance of factors" and were given to cardiologists. Essential factors, whose method of extraction has already been published in [17] are: demographic information such as age, height and weight, and clinical information and lab test results include previous and current INR, target range of INR, previous and current dose of warfarin as output variable.

The data were extracted from the patient's medical records by using a random sampling method and was used to train and evaluate the MLP. The patients with artificial heart valves were treated in the second half of 2013 at the PT Tehran Heart Center were included.

In data preprocessing step, for each variable, missing values (31 data items) are completed by mean of that variable. Then, using the Larose normalization method, all the variables were normalized to the interval $[0,1]$. In implementation step, several MLP neural networks with different number of neurons in hidden layer based on conjugate gradient training algorithm were constructed and evaluated to determine the best network for developing an intelligent system for warfarin dosing.

\section{APPLICATION}

Data of 846 patients including age, height, weight, previous and current INR, target range of INR, previous and current dose of warfarin as output variable were extracted. MLP neural networks with different structures were implemented in the MatLab programming environment. A total of nine MLP neural networks with different number of neurons in hidden layer (2 to 10 ) were created based on epochs $=1000$, goal $=0$, tangent hyperbolic activation function and conjugate gradient training algorithm. The performance of different neural networks was investigated using 10-fold cross validation and the results are compared based on disturbance rate, Mean Absolute Error (MAE) and regression coefficient (R2). The results revealed that, MLP with seven neurons in hidden layer is the best model with a MAE $=0.1$, disturbance rate $=0.33$ and R2=0.87. Therefore, this neural network was chosen to design the intelligent system for warfarin dosing. Graphical User Interface (GUI) of prediction system was created by using GUIDE in MatLab environment. Fig 1 shows an overview of data entrance page of the system.

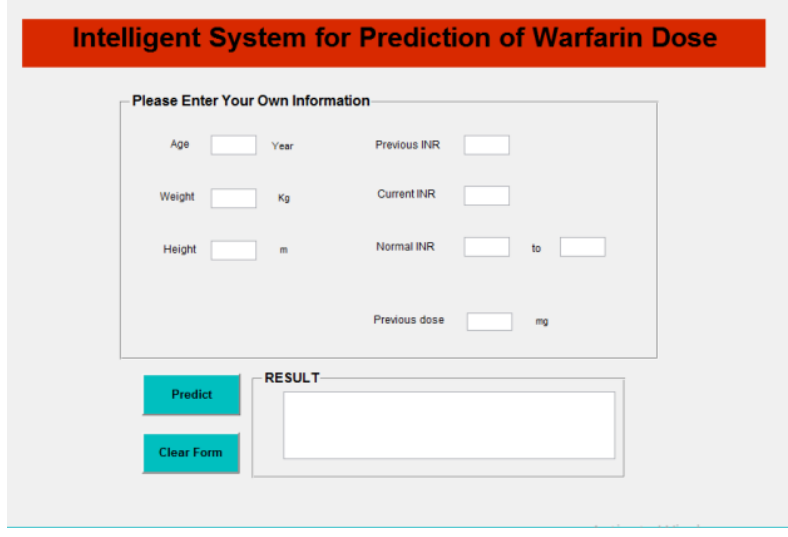

Fig 1: Overview of data entrance page

\section{DISCUSSION}

There is a large body of literature describing the development of tools to predict warfarin dose requirements for adult patient in other countries around the world. The variables included in the prediction model, the implemented methods, and the findings of related studies are shown in Table 1. 
Table 1: Characteristics of related studies

\begin{tabular}{|c|c|c|c|}
\hline $\begin{array}{l}\underset{0}{0} \\
\stackrel{0}{0} \\
\frac{0}{0} \\
0 \\
0 \\
0\end{array}$ & Variables & Method(s) & Findings \\
\hline [18] & $\begin{array}{l}\text { Age, Sex, Body Surface Area(BSA), } \\
\text { Amiodarone, Smoking, deep venous } \\
\text { thrombosis /pulmonary embolism } \\
\text { (DVT/PE), Diabetes, Cancer, } \\
\text { Hypertension, Stable INR, Stable } \\
\text { Warfarin Dosage }\end{array}$ & $\begin{array}{l}\text { Artificial Neural } \\
\text { Networks, Support } \\
\text { Vector Regression } \\
\text { (SVR), Linear } \\
\text { Multivariate } \\
\text { Regression }\end{array}$ & $\begin{array}{l}\text { Best model is Linear Multivariate } \\
\text { Regression with a MAE }=12.2 \text { and } \\
\text { RMSE }=14.51\end{array}$ \\
\hline [19] & $\begin{array}{l}\text { Age, Height, Weight, Race, Use of } \\
\text { enzyme inducers, Use of amiodarone, } \\
\text { Previous and current INR , CYP2C9, } \\
\text { VKORC1 }\end{array}$ & linear regression & $\begin{array}{l}\text { Model that is developed based on } \\
\text { clinical and genetic data } \\
\text { (MAE=8.5 [confidence interval:8-9], } \\
\mathrm{R}^{2}=43 \% \text { ) achieve better result than } \\
\text { model that is developed based on } \\
\text { only clinical data (MAE=9.9 } \\
\text { [confidence interval :9.3-10.4], } \\
\mathrm{R}^{2}=26 \% \text { ) }\end{array}$ \\
\hline []] & $\begin{array}{l}\text { Age, Weight, Height, Gender, CYP2C9, } \\
\text { VKORC1 Amiodarone, Lupus } \\
\text { Anticoagulant (LA) } \\
\text {, drinking, alanine aminotransferase } \\
\text { (ALT), Serum Creatinine (SCr), INR }\end{array}$ & $\begin{array}{l}\text { Particle Swarm } \\
\text { Optimization (PSO)- } \\
\text { ANN/SVR, RBF, BP, } \\
\text { regression }\end{array}$ & $\begin{array}{l}\text { PSO-ANN/SVR based on clinical and } \\
\text { genetic factors (MSE }=0.0258, \\
\mathrm{R}^{2}=60.9 \% \text { ) achieve better result } \\
\text { than model that is developed based } \\
\text { on only clinical data (MSE }=0.0316 \text {, } \\
\left.\mathrm{R}^{2}=53.2 \%\right)\end{array}$ \\
\hline [20] & $\begin{array}{l}\text { Gender, age, height, weight, Diabetes, } \\
\text { CYP2C9, VKORC1, INR; the level of the } \\
\text { blood alkaline phosphatase } \\
\text { (ALP), glutamic oxaloacetic } \\
\text { transaminase (GOT), glutamic } \\
\text { pyruvate transaminase (GPT), } \\
\text { thyroid-stimulating hormone } \\
\text { (TSH), free thyroxine (FT4) and the } \\
\text { concentration of blood } \\
\text { Creatinine, Concomitant } \\
\text { medication usage, Thyroid hypofunction, } \\
\text { Thyroid stimulating hormone level, High } \\
\text { creatinine, Free thyroxine concentration }\end{array}$ & $\begin{array}{l}\text { hierarchical stepwise } \\
\text { multivariate linear } \\
\text { regression }\end{array}$ & $\begin{array}{l}\text { For patients who have recently } \\
\text { undergone heart valve surgery: } \\
\mathrm{R}^{2}=34.1 \% \\
\text { For patients who had been treated } \\
\text { with warfarin more than } 3 \text { months: } \\
\mathrm{R}^{2}=50.2 \%\end{array}$ \\
\hline [21] & $\begin{array}{l}\text { Gender, age, weight, congestive heart } \\
\text { failure, thyrotoxicosis, or hepatic } \\
\text { renal dysfunction, ALT, SCr and a list } \\
\text { of medicines causing severe DDI } \\
\text { when combined with warfarin. }\end{array}$ & $\begin{array}{l}\text { k-nearest } \\
\text { neighbors (kNN), } \\
\text { model } \\
\text { tree (M5), SVR, MLP, } \\
\text { Bagged kNN, Bagged } \\
\text { SVR, Bagged MLP, } \\
\text { Bagged M5, Voting } \\
\text { with } 4 \text { classifies, } \\
\text { Bagged voting with } 4 \\
\text { classifiers }\end{array}$ & $\begin{array}{l}\text { Best model is Bagged Voting with } \\
\text { four classifiers with a mean } \\
\text { absolute error (MAE) }=0.210 \text { and } \\
\text { standard deviation of errors } \\
(\sigma(E))=0.357\end{array}$ \\
\hline
\end{tabular}

\section{CONCLUSION}

According to previous studies, predicting warfarin dose based on clinical and demographic data only obtain performance as well as or even better than experts [18, 21]. However, Various studies have shown that adding genetic data improves the performance of prediction models $[\underline{9}, \underline{19}, \underline{20}]$, the proposed model, which predicts warfarin dose appropriately based on clinical data only, is preferred because collecting genetic data is timeconsuming and costly [21]. Unfortunately, in this study, no data were available on patients' place of residence, which could be considered in future research. 


\section{AUTHOR'S CONTRIBUTION}

All the authors approved the final version of the manuscript.

\section{CONFLICTS OF INTEREST}

The authors declare no conflicts of interest regarding the publication of this study.

\section{FINANCIAL DISCLOSURE}

No financial interests related to the material of this manuscript have been declared.

\section{REFERENCES}

1. World Health Organization. Cardiovascular disease [Internet]. 2017 [cited: 2019 May 15]. Available from:

http://www.who.int/cardiovascular_diseases/en.

2. American Heart Association. February is American Heart month [Internet]. 2017 [cited: 2019 Feb 10]. Available from: https://newsroom.heart.org/events/februaryamerican-heart-monthwomen-heart-disease.

3. Mendis S, Puska P, Norrving B. Global atlas on cardiovascular disease prevention and control. Geneva: World Health Organization; 2011.

4. Bonow RO, Carabello B, de Leon AC, Edmunds LH, Fedderly B, Freed $M$, et al. Guidelines for the management of patients with valvular heart disease. Circulation. 1998; 32(5): 1486-582.

5. Rennie LJ. Using machine learning to predict the effect of warfarin on heart patients. Pennsylvania State University; 2004.

6. Silverstein A, Silverstein VB, Nunn LS. Heart Disease. Lerner Publishing Group; 2006.

7. Sohrabi MK, Tajik A. Multi-objective feature selection for warfarin dose prediction. Computational Biology and Chemistry. 2017; 69: 126-33.

8. Eriksson N, Wadelius M. Prediction of warfarin dose: Why, when and how? Pharmacogenomics. 2012; 13(4): 429-40. PMID: 22379999 DOI: 10.2217/pgs.11.184 [PubMed]

9. Tao Y, Xiang D, Zhang Y, Jiang B. Swarm ANN/SVRbased modeling method for warfarin dose prediction in Chinese. International Conference in Swarm Intelligence: Springer; 2017.

10. Saffian SM, Duffull SB, Wright DFB. Warfarin dosing algorithms under-predict dose requirements in patients requiring $\geq 7 \mathrm{mg}$ daily: A systematic review and meta-analysis. Clin Pharmacol Ther. 2017; 102(2): 297-304. PMID: 28160278 DOI: 10.1002/cpt.649 [PubMed]

11. Sharabiani A, Bress A, Douzali E, Darabi H. Revisiting warfarin dosing using machine learning techniques. Computational and mathematical methods in medicine. 2015;2015: 1-9.

12. Sohrabi MK, Tajik A. Effective feature selection of clinical and genetic to predict warfarin dose using artificial neural network. Tehran University Medical Journal. 2016; 73(12): 900-5.

13. Nielsen PB, Lundbye-Christensen S, van der Male $M$, Larsen TB. Using a personalized decision support algorithm for dosing in warfarin treatment: A randomised controlled trial. Clinical Trials and Regulatory Science in Cardiology. 2017; 25: 1-6.

14. Shahmoradi L, Langarizadeh M, Pourmand G, Fard ZA, Borhani A. Comparing three data mining methods to predict kidney transplant survival. Acta Inform Med. 2016; 24(5): 322-7. PMID: 28163356 DOI: 10.5455/aim.2016.24.322-327 [ubMed]

15. Khashei M, Bijari M. An artificial neural network (p,d,q) model for timeseries forecasting. Expert Systems with Applications. 2010; 37(1): 479-89.

16. Pavani A, Naushad SM, Kumar RM, Srinath M, Malempati AR, Kutala VK. Artificial neural networkbased pharmacogenomic algorithm for warfarin dose optimization. Pharmacogenomics. 2016; 17(2): 12131. PMID: 26666467 DOI: $10.2217 /$ pgs.15.161 [PubMed]

17. Orooji A, Langarizadeh $\mathrm{M}$, Aghazadeh $\mathrm{M}$, Kamkarhaghighi M, Ghazisaiedi M, Moghbeli F. Dosing of warfarin in Iranian adult patients with an artificial heart valve using artificial neural networks. Journal of Payavard Salamat. 2018; 12(4): 249-59.

18. Sharabiani A, Darabi H, Bress A, Cavallari L, Nutescu E, Drozda K. Machine learning based prediction of warfarin optimal dosing for African American patients. International Conference on Automation Science and Engineering; IEEE: 2013.

19. International Warfarin Pharmacogenetics Consortium, Klein TE, Altman RB, Eriksson N, Gage $\mathrm{BF}$, Kimmel SE, et al. Estimation of the warfarin dose with clinical and pharmacogenetic data. N Engl J Med. 2009; 360(8): 753-64. PMID: 19228618 DOI: 10.1056/NEJMoa0809329 [PubMed]

20. Tatarunas V, Lesauskaite V, Veikutiene A, Grybauskas $P$, Jakuska $P$, Jankauskiene $L$, et al. The effect of CYP2C9, VKORC1 and CYP4F2 polymorphism and of clinical factors on warfarin dosage during initiation and long-term treatment after heart valve surgery. J Thromb Thrombolysis. 2014; 37(2): 177-85. PMID: $23677510 \quad$ DOI: $\quad 10.1007 / \mathrm{s} 11239-013-0940-\mathrm{x}$ [PubMed]

21. $\mathrm{Hu} \mathrm{YH}, \mathrm{Wu} F$, Lo CL, Tai CT. Predicting warfarin dosage from clinical data: A supervised learning approach. Artif Intell Med. 2012; 56(1): 27-34. PMID: 22537823 DOI: $\quad 10.1016 /$ j.artmed.2012.04.001 [PubMed] 